Reka Buana : Jurnal Ilmiah Teknik Sipil dan Teknik Kimia, 3(2), 2018, page 122-127

Tersedia online di https://jurnal.unitri.ac.id/index.php/rekabuana

ISSN 2503-2682 (Online)

ISSN 2503-3654 (Cetak)

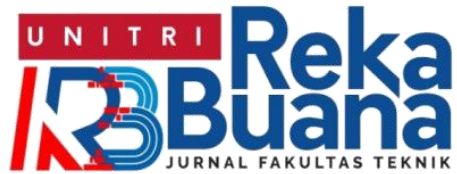

\title{
Review Kuat Tekan Beton Polos dari Perspektif Mekanika Fraktur
}

\author{
Danang Murdiyanto, Sunik ${ }^{2}$, Benedictus Sonny Yoedono ${ }^{3}$, Agnes Hanna Patty ${ }^{4}$ \\ 1,2,3,4 Fakultas Teknik Universitas Katolik Widya Karya Malang \\ e-mail : danang_t.mesin@widyakarya.ac.id
}

\begin{abstract}
Concrete is a discreet material that consist of aggregate as filler and cement paste (matrix) as binder. Both of them work together as a composite or monolithic mechanism, depends on the interface zone characteristic that developed by aggregate. Monolithic mechanism leading to failure catastrophically (brittle and instantly), while composite mechanism prevails failure occurs gradually. Monolithic mechanism maybe found in high strength concrete where hardness and stiffness of aggregate are compatible with their matrix. At the moment when the matrix tensile strength $\left(f_{t}\right)$ is reached. The cracks will propagate quickly cutting both aggregates and matrix, as well at once. Contrary to the composite condition, when the matrix tensile strength is reached, the aggregate will take over the load and the crack will propagate through the interface zone. The perspective of fracture mechanics and the failure parameters explain the mechanism of crack propagation based on the energy principles. This investigation reviews the phenomenon of concrete compressive strength with angular aggregates compared to rounded aggregates on cylindrical specimens with diameter (d) $15 \mathrm{~cm}$ and height (h) $30 \mathrm{~cm}$ of the same compressive strength. The difference between them, shows the tendency of the influence of the interface zone as traction, which significantly contributes to the performance capacity before collapse.
\end{abstract}

Keywords: compressive strength; fracture mechanic; performance capacity

\section{PENDAHULUAN}

Beton digolongkan sebagai material diskrit yang terdiri atas dua komponen utama yaitu agregat sebagai pengisi filler dan pasta semen (matriks) sebagai binder; keduanya terhubungkan melalui interface zone. Dalam mekanika fraktur, interface zone yang dikondisikan secara signifikan oleh karakteristik agregat (permukaan, kekakuan /kekerasan, geometri, dll), berdampak terhadap traksi sebagai media laju pelepasan energy regangan atau yang dikenal sebagai fracture energy. Shah [1] memformulasikan 'keruntuhan' sebagai laju pelepasan energi regangan bagi material beton yang kuasi-regas (composite mechanism) yaitu:

$$
G_{q}=G_{c}+G_{\sigma}
$$

dimana:

$G_{q}=$ laju pelepasan energi regangan untuk material kuasi-regas

$G_{c}=$ laju pelepasan energi regangan kritis untuk material elastik

$G_{\sigma} \quad=$ laju pelepasan energi regangan karena closing pressure / traksi

Pada kasus material elastik linier (monolitic mechanism/getas), persamaan (1) menjadi :

$$
G_{q}=G_{c}, \ldots(2) \text { dan } G_{q}=G_{\sigma} \ldots(3)
$$

untuk material daktail. Fenomena ini ditunjukkan berturut-turut pada Gambar 1a, dan $1 \mathrm{~b}$ dalam bentuk diagram bebandeformasi untuk elastik linier bagi yang monolitik, dan kuasi-regas bagi yang komposit. 


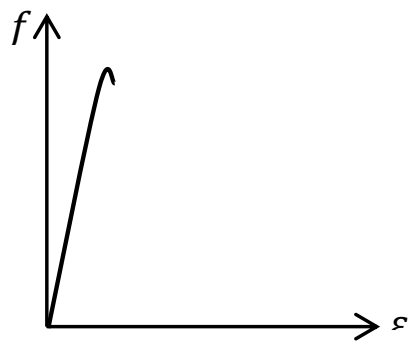

(a)

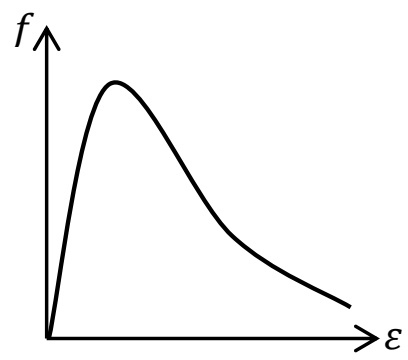

(b)

Gambar 1. Pola keruntuhan material beton untuk kriteria fraktur a) getas, b) kuasi regas

Sebuah kenyataan adalah bahwa, struktur beton penuh dengan retak awal. ACI (1989) menyatakan dengan sangat jelas, concrete structures are full of crackss ${ }^{[2]}$. Dari sudut pandang strength of materials lubang berdampak pada pengurangan penampang, diikuti oleh peningkatan tegangan ' $f$ ' yang apabila melampaui ambang batas, akan menyebabkan keruntuhan. Sebaliknya, dari sudut pandang mekanika fraktur, intensitas tegangan ' $K$ ' yang relatif tinggi eksis pada zona disekitarnya lubang ; semakin tajam ujung lubang (cracktip), intensitas tegangan $K$ semakin tinggi. Sebagaimana definisi keruntuhan menurut mekanika tegangan:

$$
\begin{aligned}
& f<f_{y} \text { (kriteria leleh) } . \\
& f<\bar{f} \text { (kriteria service) }
\end{aligned}
$$

definisi keruntuhan menurut mekanika fraktur

$K<K_{c}$ atau $G<G_{c}$ (kriteria fraktur)

dimana, $f=$ tegangan

$\mathrm{K}=$ faktor intensitas tegangan

$$
\mathrm{G} \quad=\text { energy fraktur }
$$

$\mathrm{K}$ dan $\mathrm{G}$ dihubungkan oleh persamaan:

$$
K=\sqrt{E G}
$$

$K_{c}$ maupun $G_{c}$ menunjukkan nilai kritis dari faktor intensitas tegangan dan energi fraktur yang dikenal sebagai ketegaran fraktur (fracture toughness); retak akan merambat bila nilai kritis ini dilampaui. Interface zone yang terbentuk karena angularitas, berpotensi berperan sebagai medan perambatan retak (composite mechanism) sebagaimana ditunjukkan pada Gambar 2a. Pada kasus ini ketegaran fraktur diformulasikan oleh persamaan 1. Ketegaran fraktur menurut persamaan 2 diaplikasikan pada kasus monolitik (monolithic mechanism) pada Gambar 2b dimana perambatan retak terjadi begitu cepat memotong baik matriks maupun agregat sekaligus. Hal ini terjadi pada beton mutu tinggi dimana kekakuan, kekerasan dan modulus elastisitas agregat berimbang/kompatibel dengan matriksnya.

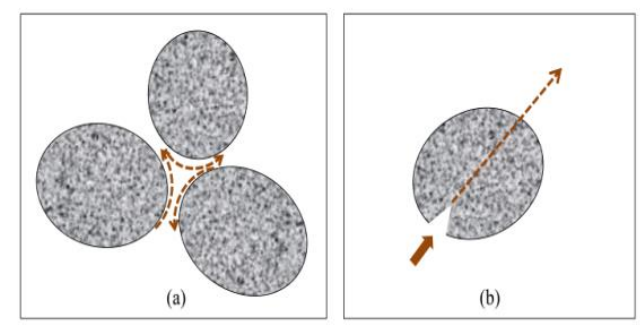

Gambar 2. Mekanisme perambatan retak

a) komposit, b) monolitik 
Material beton dengan agregat yang angular juga memiliki potensi untuk menyumbangkan daktilitas sebagai akibat dari terbentuknya retak mikro di ujung retak aktual sebagaimana ditunjukkan pada Gambar $3^{[3][4]}$. Dalam hal ini retak mikro berperanan sebagai penahan retak (crack arrester) sedemikian rupa dan menghadirkan decending part pada Gambar 1b

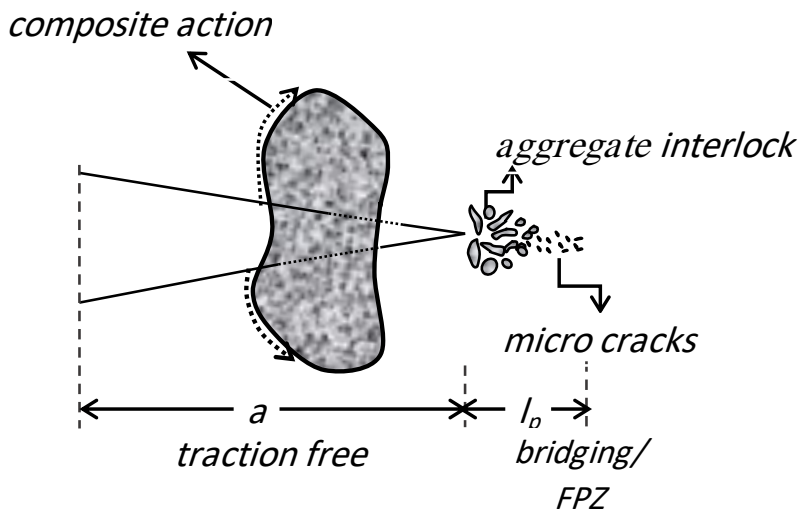

Gambar 3. Zona proses fraktur - composite mechanism

Maji dan Shah $(1998)^{[5]}$, menggunakan laser bolography untuk mengamati terjadinya retak awal dan propagasinya dimulai pada tahap elastik, inelastik, dan runtuh (Gmb 4.a , 4.b, 4.c, 4.d, 4.e, 4.f, 4.g).

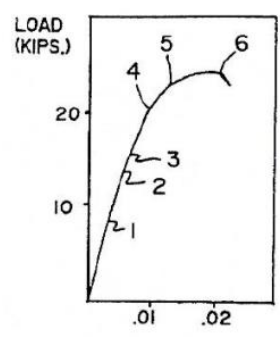

(a)

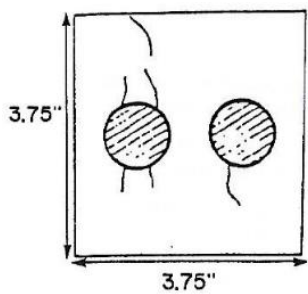

(e)

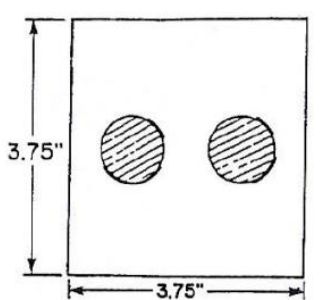

(b)

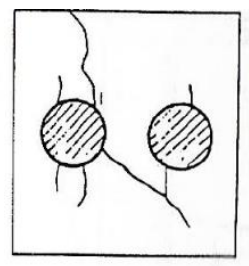

$(f)$
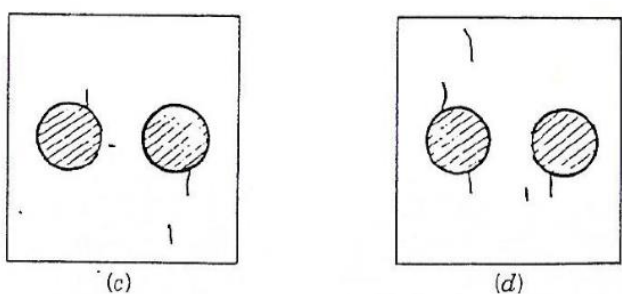

(d)

Gambar 4. Propagasi retak pada model pelat beton yang diberi beban tekan uniaxial, diamati menggunakan laser bolography : a) kurva beban-perpindahan, b) pola retak pada titik 1, c) pola retak pada titik 2, d) pola retak pada titik 3, e) pola retak pada titik 4, f) pola retak pada titik 5, dan g) pola retak pada titik 6 
Sejauh ini, investigasi/ penelitian telah banyak dilakukan terhadap kuat tekan beton sebagai dasar untuk memprediksi karakteristik kekuatannya $^{[6]}$. Disamping postulasi dasar yang selama ini digunakan yaitu $f^{\prime}{ }_{c}=\frac{P_{c r}}{A}[] \quad$ sebagai kuat tekan karakteristik, terdapat banyak metode berbeda juga digunakan, Zain M.F.M, et al (2010) memperkenalkan multivariable power equation sebagai sebuah metode yang efektif untuk memprediksi kekuatan; dalam bentuk umum dinyatakan sebagai ${ }^{[8]}$

$$
y=a_{0} X_{1}^{a_{1}} X_{2}^{a_{2}} X_{3}^{a_{3}} \ldots \ldots \ldots \ldots X_{n}^{a_{n}} \ldots
$$

Jika diaplikasikan pada perhitungan kuat tekan beton pada umur tertentu, persamaan (8) menjadi :

$$
\begin{aligned}
& f_{\text {age }}= \\
& \begin{array}{l}
a_{0} C^{a_{1}} W^{a_{2}} F A^{a_{3}} C A^{a_{4}} \rho^{a^{5}}(w / c)^{a^{6}} \ldots \text { (9) } \\
\operatorname{dimana} C \quad=\text { semen } \\
W \quad=\text { air } \\
F A=\text { pasir } \\
C A=\text { agregat } \\
\rho \quad=\text { berat jenis beton } \\
w / c=\text { faktor air semen }
\end{array}
\end{aligned}
$$

adalah variabel-variabel yang menentukan nilai kuat tekan beton. Berdasarkan sudut pandang mekanika fraktur, variabel-variabel ini merupakan faktor-faktor stabilisasi pertumbuhan retak (factor stability crack growth). Sidney Mindess dan J. Francis Young (1981) mengeksplorasi tiga faktor utama yang berperan dalam proses stability crack, growth yaitu, agregat, zona retak mikro (Gambar 3) dan tipe pembebanan ${ }^{[9]}$. Adam M. Neville (1997) mengkaji sebuah hubungan korelasi antara aggregat bond (dipengaruhi oleh angularitas) dengan modulus elastisitas beton. Perbedaan modulus elastisitas agregat dan pasta semen menunjukkan karakteristik tegangan pada interface zone yang terimplementasikan pada hubungan tegangan dan regangan ${ }^{[10]}$

Penelitian ini bertujuan untuk mereview kuat tekan beton normal dengan angularitas agregat yang berbeda dipandang dari perspektif mekanika fraktur. Benda uji sejumlah 18 silinder dengan diameter $15 \mathrm{~cm}$ dan tinggi $30 \mathrm{~cm}$, terdiri dari 9 silinder dengan agregat angular (bersudut) dan 9 silinder dengan agregat rounded (bulat). Campuran menggunakan Semen Portland Tipe 1. Silinder diuji tekan dan dihitung kekuatan tekannya $\left(f^{\prime}\right)$. Hasil kekuatan tekan dibandingkan dan dianalisis.

\section{HASIL DAN PEMBAHASAN}

Hasil pengujian dapat dilihat pada Grafik 1, dengan sumbu x adalah benda uji dan y adalah kuat tekan beton $f_{c}^{\prime}(\mathrm{MPa})$.

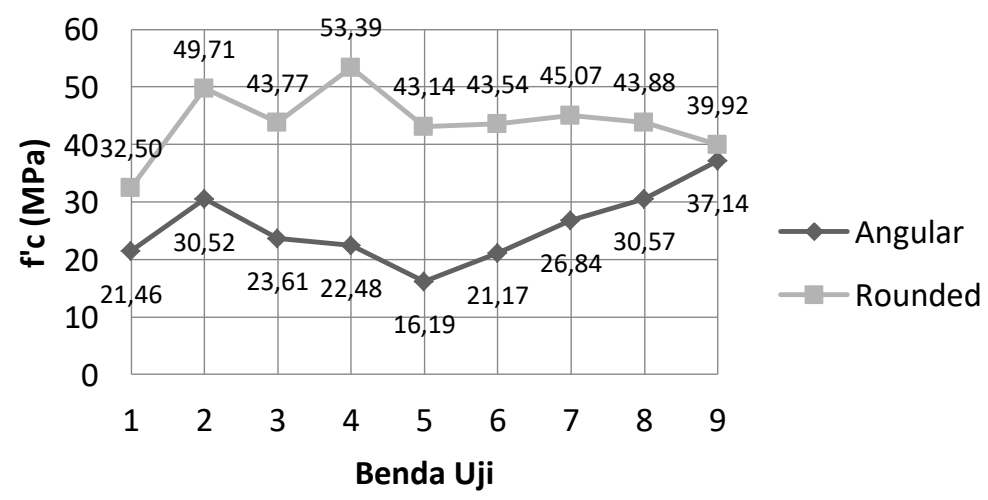

Grafik 1. Perbandingan kuat tekan beton $\left(f^{\prime}\right)$ agregat angular dan rounded 
Perbedaan nilai kuat tekan antara beton dengan agregat angular dan beton dengan agregat rounded secara signifikan ditentukan oleh pola perambatan. Saat pembebanan (loading) benda uji menyerap energi. Energi yang diserap ini akan didisipasi / dilepaskan seiring dengan pelepasan beban (unloading). Kecepatan pelepasan energi ini sangat tergantung pada karakteristik interlock antara agregat dengan matriks melalui interface zone. Material beton dengan agregat angular, interface zone mengembangkan traksi sedemikian rupa sehingga retak dimulai pada tahap inelastis merambat melalui interface zone; ketegaran fraktur dinyatakan oleh Persamaan.1. Sebaliknya, pada beton dengan agregat rounded, traksi (dalam terminology mekanika fraktur dikenal sebagai closing pressure) relatif tidak ada; energi yang diserap saat loading semata-mata digunakan bagi pembentukan retak yang dilepaskan seketika memotong baik agregat, juga matriksnya sehingga ketegaran fraktur dinyatakan dalam Persamaan 2. Beban tepat saat unloading $P_{c r}$ definisinya adalah beban runtuh, selanjutnya kuat tekan ditentukan sebagai $f_{c}^{\prime}=\frac{P_{c r}}{A}$.

\section{KESIMPULAN}

Berdasarkan hasil pengujian, dapat disimpulkan bahwa benda uji dengan agregat rounded lebih tinggi kuat tekannya dibandingkan dengan yang angular. Hal ini dapat dijelaskan sebagai berikut:

1. Pencapaian beban runtuh $P_{c r}$ pada beton dengan sifat monolitik (berarti getas), berpotensi lebih tinggi, karena tidak ada energi yang terbuang untuk perambatan retak. Yang dilepaskan hanya energi untuk pembentukan retak sebagaimana diformulasikan pada Pers. 2.
2. Pada beton dengan sifat komposit (berarti kuasi-regas), sebagian energi digunakan untuk formasi retak (crack formation) beban retak pertama terjadi pada limit elastis yang lebih rendah dari $P_{c r}$ pada butir 1, sebetulnya belum mengakibatkan unloading. Beban, sesungguhnya masih meningkat sampai pada tahap ketidakstabilan deformasi (unstable deformation) dimana kehancuran total terjadi. Beban akhir ini merupakan $P_{c r}$ pada kasus kuasi-regas, yang lebih rendah dari $P_{c r}$ pada kasus monolitik

\section{DAFTAR PUSTAKA}

1. Shah, S.P, Swartz,S.E., Ouyang, C, "Fracture Mechanics of Concrete: Applications of Fracture Mechanics to Concrete, Rock, and Other Quasi-Brittle Materials'John Wiley and and Sons Inc.

2. ACI Committee 446-91.1989."'Fracture Mechanics of Concrete : Concepts, Models, and Determination of Material Properties,

3. Patty, A.H., 2004. " Analisis Mekanika Fraktur Dïmplementasikan Pada Beton Ringan Serat Baja Dengan Bukaan Tarik Tunggal," Disertasi, ITB

4. Patty, A. H., Oesman, Mardiana. 2009. "A Study on Reinforced Concrete Ductility Based on Open Tensile Mode Fracture Using Residual Strength Analysis", International Conference on Sustainable Infrastructure and Built Environment in Developing Countries, ITB

5. Maji, A.K., and Shah, S.P. 1998. "Application of Acoustic Emission and Laser Holography to Study Microfracture in Concrete," Nondestructive testing, ACI SP-112

6. Kabir, Ahsanul., Hasan, Monjurul., Miah, Khasro. 2012. "Predicting 28 Days 
Compressive Strength of Concrete from 7 Days Result". Proc. of Int. Conf. on Advances in Design and Construction of Structures, ACEE

7. ASTM C 39/ C39M - 18 Standard Test Method for Compressive Strength of Cylindrical Concrete Specimens

8. Zain M.F.M., Suhad M.Abd, Hamid R and Jamil M. 2010, "Potential for Utilizing Concrete Mix Properties to Predict Strength at Different Ages". Journal of Applied Science, Vol.10(22),pp 2831-2838

9. Mindess, Sidney., Young,Francis J. 1981. "Concrete".Prentice-Hall Inc. Engelwood Cliffs, New Jersey

10. Neville, Adam.M. 1997. "Aggregate Bond and Modulus of Elasticity Concrete". ACI Material Journal - Technical Paper. Tittle no 94-M9 